\title{
Successful treatment of superior mesenteric artery syndrome by endoscopic ultrasound-guided gastrojejunostomy
}
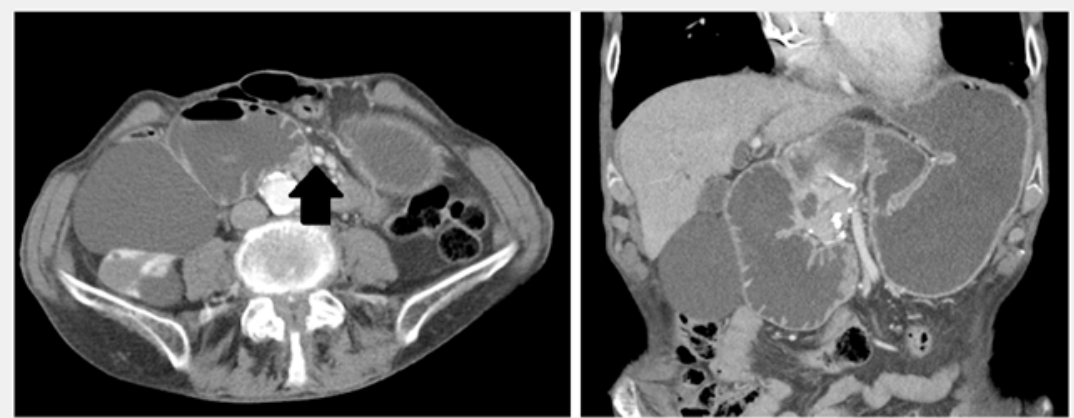

Fig. 1 Computed tomography imaging revealing significant gastric distention and dilatation of the proximal duodenum. A high-grade stenosis was identified at D3 caused by direct extrinsic compression by the superior mesenteric artery and vein.

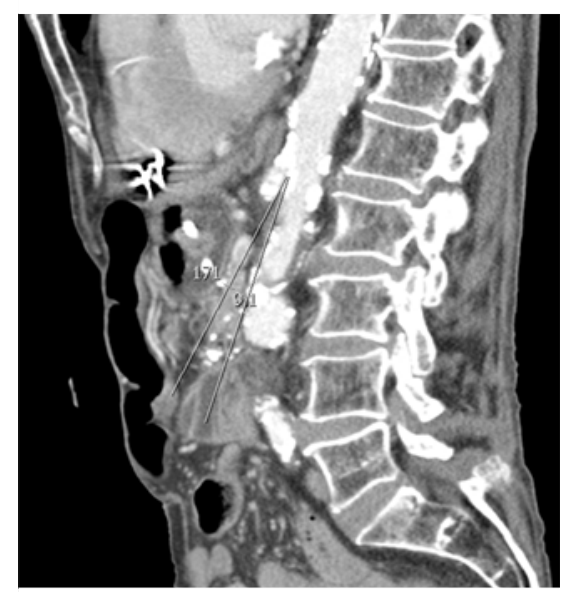

- Fig. 2 Sagittal computed tomography image demonstrating a severely reduced aortomesenteric angle $\left(9.1^{\circ}\right)$. Significant gastric dilatation and vascular calcifications can also be seen.

An 88-year-old man with a history of extensive cardiovascular co-morbidities was admitted to our tertiary center following prolonged vomiting, anorexia, and upper abdominal pain. He had lost 10 kilograms over the course of 4 months as a result. An abdominal computed tomography (CT) scan was performed to rule out neoplasia. Surprisingly, the scan revealed extensive gastroduodenal distention and a high-grade stenosis of the

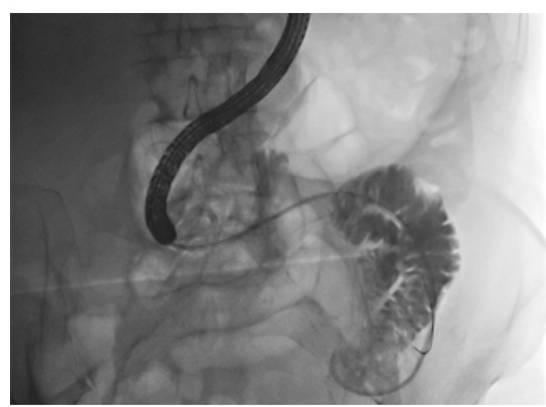

- Fig. 3 Under fluoroscopic guidance and direct endoscopic visualization, a guidewire was advanced through the compressed bulbar region into D2 and through the stenosis at D3.

third part of the duodenum (D3) caused by extrinsic compression by the superior mesenteric artery ( $\mathbf{F i g . 1}$, arrow). Furthermore, a significantly reduced aortomesenteric angle was identified $\left(9.1^{\circ}\right.$, normal: $25-60^{\circ}$ ) ( Fig. 2 ); these findings are compatible with superior mesenteric artery syndrome [1]. Nasogastric tube decompression and parenteral feeding were commenced, resulting in only temporary relief of symptoms. Unfortunately, endoscopic placement of a nasojejunal feeding tube also failed.

Only very recently has endoscopic ultrasound (EUS)-guided gastroenterostomy also been evaluated in the context of a

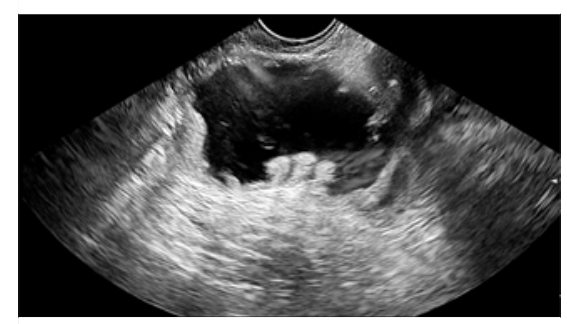

- Fig. 4 Endoscopic ultrasound image showing dilatation of the targeted jejunal loop.

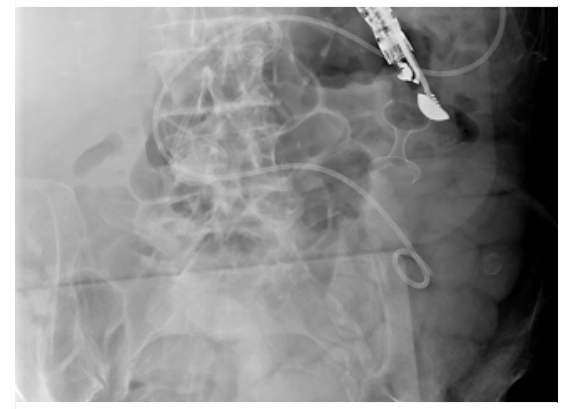

- Fig. 5 Fluoroscopic image following successful deployment of the lumen-apposing stent connecting the lower gastric wall with the jejunal lumen, where the nasojejunal catheter is still in place. An old dislocated double-pigtail stent can be seen in D2; it was used approximately a decade ago for successful drainage of a pancreatic pseudocyst. No extraction was attempted owing to the limited clinical implications and risk of dislocating the nasojejunal catheter.

benign gastric outlet obstruction [2,3]. Because our patient was deemed unfit to undergo surgery, this technique was proposed to the patient and his family, who consented to the procedure. Under endoscopic and fluoroscopic guidance, a 0.035-inch guidewire was advanced through the extrinsic stenosis of D3 ( $\triangleright$ Fig.3) and subsequently exchanged for a nasobiliary catheter. Water was infused into the jejunum ( $\triangleright$ Video 1 ), dilating the latter and facilitating visualization on EUS ( $>$ Fig.4). Lastly, a $20 \times$ $10-\mathrm{mm}$ lumen-apposing metal stent 


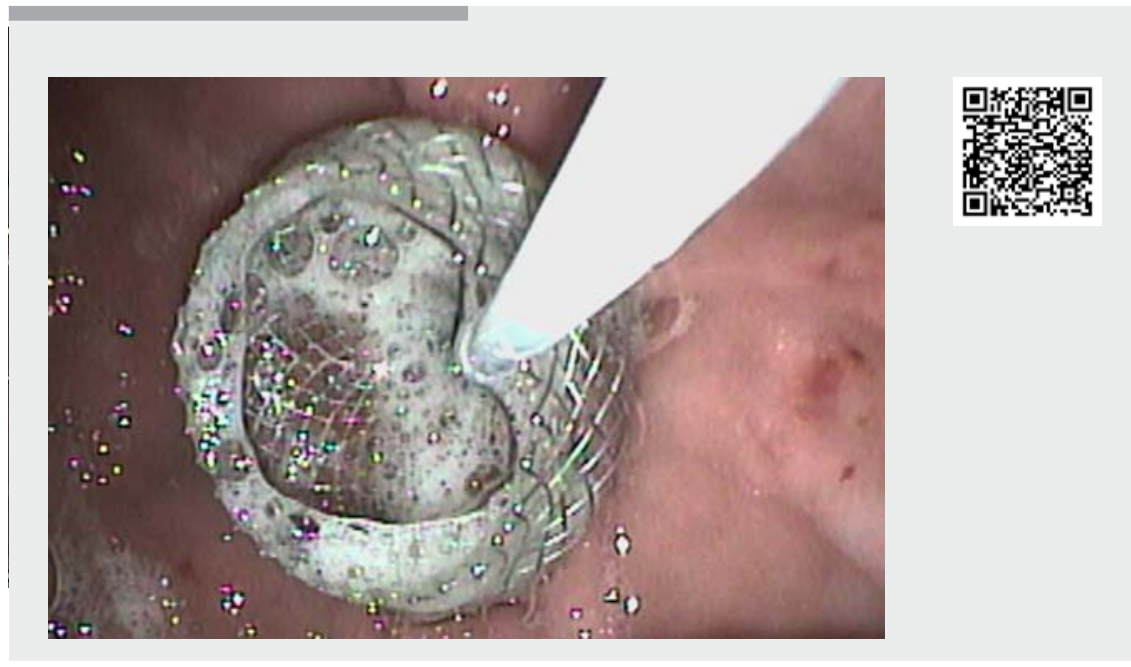

Video 1 Endoscopic ultrasound-guided gastrojejunostomy for treatment of superior mesenteric artery syndrome.

(LAMS) with an electrocautery-enhanced delivery system (Hot AXIOS; Boston Scientific, Marlborough, Massachusetts, USA) was deployed through the gastric wall into the dilated jejunum ( $\mathbf{F i g . 5}$ ), creating a gastrojejunostomy. No complications occurred and the patient was started on clear liquids the same evening. During the following days, intake increased progressively and the patient was discharged on day 7.

This video case illustrates the diverse indications for which this minimally invasive technique can be used and confirms previous work that even patients with benign disease can benefit from EUSguided gastroenterostomy.

Endoscopy_UCTN_Code_TTT_1AS_2AB

\section{Competing interests}

M. Bronswijk received travel grants from Prion Medical, Taewoong, and Takeda. S. van der Merwe holds the Cook Chair in Interventional Endoscopy, the Boston Chair in Therapeutic EUS, as well as consultancy agreements with Pentax and Olympus.

The other authors declare no competing interests regarding this specific paper.

\section{The authors}

Michiel Bronswijk, Lennert Fransen, Giuseppe Vanella, Martin Hiele, Schalk van der Merwe Department of Gastroenterology and Hepatology, University Hospitals Leuven, KU Leuven, Belgium

\section{Corresponding author}

\section{Michiel Bronswijk, MD}

Herestraat 49, 3000 Leuven, Belgium

Fax: +32-47-3886089

mjh.bronswijk@gmail.com

\section{References}

[1] Neri S, Signorelli SS, Mondati E et al. Ultrasound imaging in diagnosis of superior mesenteric artery syndrome. J Intern Med 2005; 257: 346

[2] McCarty TR, Garg R, Thompson CC et al. Efficacy and safety of EUS-guided gastroenterostomy for benign and malignant gastric outlet obstruction: a systematic review and meta-analysis. Endosc Int Open 2019; 7: 1474-1482

[3] James TW, Greenberg S, Grimm IS et al. EUS-guided gastroenteric anastomosis as a bridge to definitive treatment in benign gastric outlet obstruction. Gastrointest Endosc 2020; 91: 537-542

\section{Bibliography}

DOI https://doi.org/10.1055/a-1190-3228

Published online: 19.6.2020

Endoscopy 2021; 53: 204-205

Georg Thieme Verlag KG

Rüdigerstraße 14 ,

70469 Stuttgart, Germany

ISSN 0013-726X

\section{ENDOSCOPY E-VIDEOS}

https://eref.thieme.de/e-videos

回直 Endoscopy E-Videos is a free rection, reporting 回社: on interesting cases and new

techniques in gastroenterological endoscopy. All papers include a high quality video and all contributions are freely accessible online.

This section has its own submission website at https://mc.manuscriptcentral.com/e-videos 